\title{
Thoracic complications of Lemierre syndrome
}

\author{
Russell Thomas Gowan MD ${ }^{1}$, Reza John Mehran MD FCCP ${ }^{1}$, Pierre Cardinal MD², \\ Gwynne Jones MB BS ${ }^{2}$ \\ ${ }^{1}$ Division of Thoracic Surgery and ${ }^{2}$ the Program of Critical Care, Division of Medicine, \\ Ottawa Hospital, Ottawa, Ontario
}

RT Gowan, RJ Mehran, P Cardinal, G Jones. Thoracic complications of Lemierre syndrome. Can Respir J 2000;7(6):481-485.

Lemierre syndrome is a severe, septicemic illness most commonly caused by the anaerobic Gram-negative bacillus Fusobacterium necrophorum. It is characterized by an acute oropharyngeal infection, with secondary septic thrombophlebitis of the internal jugular vein and frequent metastatic infections. This report of a patient with the Lemierre syndrome is complemented by a review of the literature on the subject.

Key Words: Hemoptysis; Lemierre syndrome; Septicemia; Thrombophlebitis

\section{Complications thoraciques du syndrome de Lemierre}

RÉSUMÉ : Le syndrome de Lemierre est une maladie septicémique grave le plus souvent causée par un bacille gram-négatif anaérobie, Fusobacterium necrophorum. Il se caractérise par une infection oro-pharyngée aiguë accompagnée de thrombophlébite septique secondaire de la jugulaire interne et par de fréquentes infections métastatiques. Nous présentons ici le cas d'un patient atteint du syndrome de Lemierre, ainsi qu'une revue de la littérature sur le sujet.
$\mathrm{L}$ emierre syndrome was first reported by Courmont and Cade in 1900 (1), but it was best characterized by Lemierre in his review of 20 cases in 1936 (2). In the preantibiotic era it was not uncommon, and often had a fulminant and fatal course (2). Since then, with the common practice of treating oropharyngeal infections with antibiotics, its reported incidence has greatly declined and is currently estimated at 0.8/1,000,000 persons/year (3). The mean age of patients is between 17 and 22 years, with two-thirds of patients being male (3-5). The illness typically begins in a previously healthy patient who first develops an acute tonsillitis or pharyngitis (5). Septicemia usually occurs within a week, although the signs and symptoms of the oropharyngeal infection may have abated, even without previous antibiotic treatment, by the time that the patient develops internal jugular vein thrombosis and metastatic infection (6). Despite its unique morphological appearance on Gram stain, Fusobacterium necrophorum, by far the most common causative organism in this syndrome, is seldom identified initially (4). To complicate matters further, the organism may take several days to grow in culture (7). These factors, along with the nonspecific physical findings of internal jugular vein thrombophlebitis and physical findings of metastatic infection, frequently lead to a delay in diagnosis or a misdiagnosis of endocarditis, mononucleosis or Legionnaires disease (5). Septic emboli are frequent, especially to the lungs (3-5). Respiratory failure 


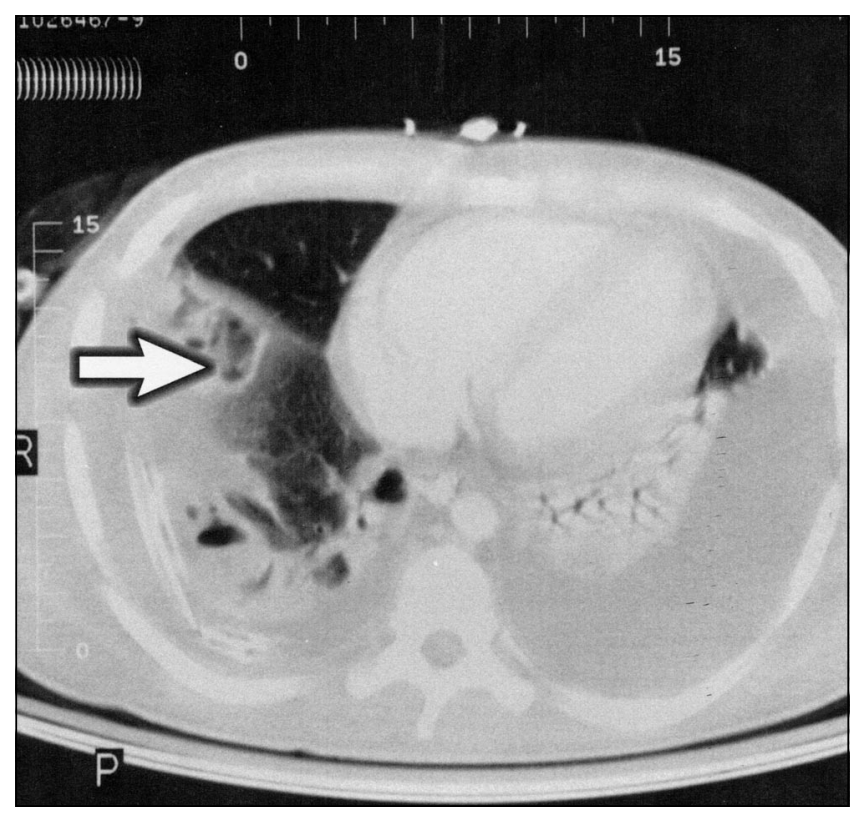

Figure 1) Computed tomography scan of the lower thorax. Note the lung abscesses (arrow) and the bilateral pleural effusions

is not uncommon, and death still occurs (3-5,8-12). It is not surprising that patients are usually quite ill and have a protracted clinical course.

We reviewed the cardiothoracic complications of this illness. The details of the case presented here and 58 cases collected since 1990 form the basis of this discussion.

\section{CASE PRESENTATION}

A previously healthy 27 -year-old male presented 10 days before admission with a sore throat and enlarged anterior cervical lymph nodes. He was initially diagnosed as having a viral pharyngitis. He then developed fever, hemoptysis, orthopnea, right-sided pleuritic chest pain, nausea, vomiting, epigastric pain and right-sided knee pain with stiffness.

On admission, he looked ill with a temperature of $39.6^{\circ} \mathrm{C}$, pulse rate of 120 beats/min, blood pressure of $100 / 60 \mathrm{mmHg}$ and respirations of 36 breaths/min. He had scleral icterus, nonexudative pharyngitis, and mild bilateral anterior cervical, occipital and supraclavicular adenopathy. There was mild induration and tenderness of the right jugulodigastric soft tissues. On auscultation of his chest, he had decreased air entry bilaterally with bibasilar rales. He had nontender hepatomegaly $(20 \mathrm{~cm})$, and pain of his right knee on active and passive motion but without signs of inflammation or effusion.

Laboratory values were as follows: white blood cell count of $18,900 / \mathrm{mm}^{3}$ and platelet count of $23,000 / \mathrm{mm}^{3}$; total bilirubin $79 \mu \mathrm{mol} / \mathrm{L}$ (normal 0 to $20 \mu \mathrm{mol} / \mathrm{L}$ ); aspartate aminotransferase $38 \mathrm{U} / \mathrm{L}$ (normal 5 to $38 \mathrm{U} / \mathrm{L}$ ); alkaline phosphatase $236 \mathrm{U} / \mathrm{L}$ (normal 25 to $100 \mathrm{U} / \mathrm{L}$ ). Monospot test was negative. Arterial blood gas values (patient breathing 100\% oxygen) were: $\mathrm{pH} 7.52$; partial pressure of carbon dioxide $34 \mathrm{mmHg}$; partial

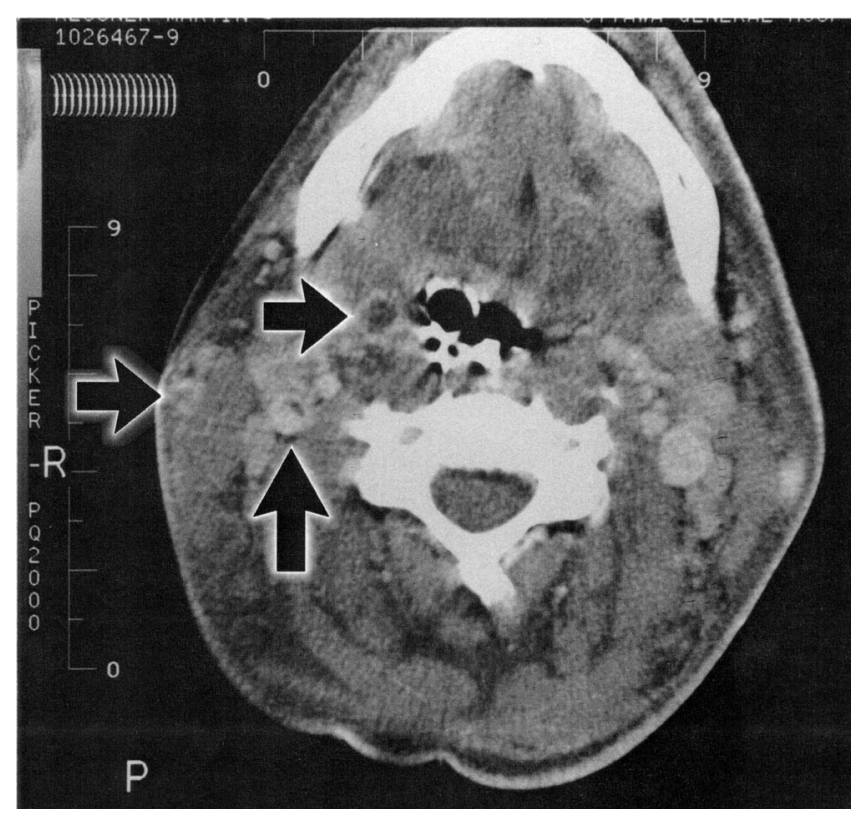

Figure 2) Computed tomography scan of the neck. Note the right tonsillar abscess (upper horizontal arrow), the complete thrombosis of the right external jugular vein (lower horizontal arrow) and the nonocclusive thrombosis of the right internal jugular vein (vertical arrow)

pressure of oxygen $61 \mathrm{mmHg}$; and bicarbonate $30 \mathrm{mEq} / \mathrm{L}$. Initially a chest radiograph showed moderate bilateral loculated pleural effusions and diffuse airspace disease involving the right lower, left upper and left lower lobes. Blood cultures were obtained, and he was treated with intravenous cefuroxime and erythromycin for presumed pneumonia.

Two days later he developed respiratory failure necessitating ventilatory support. Chest radiographs showed increasing pleural effusions and worsening airspace disease compatible with adult respiratory distress syndrome (ARDS). A computed tomography (CT) scan of the chest (Figure 1) demonstrated patchy consolidation of all lobes, moderate bilateral loculated pleural effusions, right paratracheal lymphadenopathy and bilateral lung nodules with cavitation, in keeping with multiple septic emboli and lung abscesses. Transesophageal echocardiogram showed no evidence of endocarditis. Bilateral thoracostomy tubes were inserted. On the fifth hospital day, F necrophorum was isolated from the admission blood cultures and antibiotics were changed to intravenous penicillin G. Three days later the diagnosis of Lemierre syndrome was made after a CT scan of the neck demonstrated an $8 \mathrm{~mm}$ right tonsillar abscess, nonocclusive thrombosis of the right internal jugular vein and complete thrombosis of the right external jugular vein (Figure 2). He was treated with intravenous heparin to produce anticoagulation. Repeat CT scans of the chest and neck suggested bilateral empyemas and a resolving tonsillar abcess. The empyemas and two superficial lung abscesses were drained via bilateral muscle-sparing thoracotomies. Cultures of purulent pleural fluid were sterile. He improved and was extubated on day 16 in the hospital. The following morning during chest physiotherapy, he had asphyxiating massive hemoptysis 
TABLE 1

Thoracic complications of Lemierre syndrome - review of the literature from 1990 to 1999

\begin{tabular}{|c|c|c|}
\hline Complication & Number of reported cases (\%) & Reference(s) \\
\hline Pulmonary complications (total) & $46(78)$ & \\
\hline Pneumonia (total) & $30(51)$ & $6,8-11,16,18,19,21-24,27-32,40,45,{ }^{*}$ \\
\hline Necrotizing pneumonia & $6(10)$ & $10,11,28$ \\
\hline Lung abscess & $18(31)$ & $11,13,14,20,22,23,26,28,31,35,36,^{*}$ \\
\hline Respiratory failure & $17(29)$ & $9-13,18,22-24,32,37,45,{ }^{*}$ \\
\hline Bronchiectasis & $1(1.7)$ & 21 \\
\hline Massive hemoptysis & $1(1.7)$ & * \\
\hline Pleural complications (total) & $21(36)$ & \\
\hline Pleural effusion & $19(32)$ & $6,8,10,11,13,16,19-23,27,29,37,46,{ }^{*}$ \\
\hline Empyema & $8(14)$ & $9-11,20,27,35, *$ \\
\hline Supraventricular tachycardia & $1(1.7)$ & 11 \\
\hline Purulent pericarditis & $1(1.7)$ & 8 \\
\hline Mediastinal complications (total) & $2(3)$ & \\
\hline Mediastinitis & $2(3)$ & 8 \\
\hline Mortality & $6(10)$ & $8-12$ \\
\hline Cardiothoracic complications (total) & $50(85)$ & \\
\hline No cardiothoracic complications (total) & $9(15)$ & $17,38,39,41-44$ \\
\hline Total reported cases & 59 & \\
\hline
\end{tabular}

${ }^{*}$ Complication of present case

from the right middle lobe. A left-sided, double-lumen endotracheal tube was placed for pulmonary isolation, and anticoagulation therapy was reversed. The hemoptysis resolved, and shortly after he was extubated. The patient was discharged home one week later on a 30-day course of oral penicillin. A repeat CT scan showed complete resolution of pulmonary abscesses and jugular vein thrombosis.

\section{DISCUSSION}

$F$ necrophorum is a Gram-negative, nonmotile, obligate anaerobe found as part of the indigenous flora of the upper respiratory, gastrointestinal and genitourinary tracts (13). Unlike most other anaerobes, some strains have the unique ability to produce toxins, such as lipopolysaccharide endotoxin, leukocidin and hemolysin, which allows them to invade as a primary pathogen in a previously healthy host $(13,14)$. What causes the organism to become invasive is unknown, although breaks in the oropharyngeal mucosa caused by surgery or viruses have been implicated $(8,9)$. Oropharyngeal infections can then spread via direct extension, lymphatic extension or perivascular extension from the submandibular, peritonsillar, retropharyngeal, parotid or masticator spaces to the lateral pharyngeal space $(15,16)$. The posterior (retrostyloid) compartment of $F$ necrophorum contains the carotid artery, cranial nerves IX to XII and the internal jugular vein (16). Infection of this space can lead to septic thrombophlebitis of the internal jugular vein, with multiple thromboem- bolic metastases, especially to the heart, liver, soft tissues, large joints, pleura and lungs (10,17-21).

Cardiothoracic complications occurred in $85 \%$ of patients reviewed (Table 1). Patients with septic embolization to the lungs often complain of dyspnea, pleuritic chest pain, fever and hemoptysis. Arterial blood gases invariably show some degree of hypoxemia and abnormal alveolar-arterial oxygen gradient (22). Diffuse, bilateral, nodular or patchy infiltrates are the most common findings on chest $\mathrm{x}$-ray. These represent either pneumonias or septic pulmonary infarcts (1), and were the most common cardiothoracic complications of Lemierre syndrome (incidences of $51 \%$ and $32 \%$, respectively) (Table 1).

As mentioned previously, $F$ necrophorum can produce virulent toxins. These may cause pneumonias to necrotize $(10 \%)$ and septic pulmonary infarcts to cavitate. The latter will lead to multiple pulmonary abscesses (31\%) or, more rarely, pneumatoceles $(1.7 \%$ ) (Table 1). CT is invaluable in identifying these and other cardiothoracic complications (23).

Pleural complications are also quite prevalent: over onethird of patients (21 of 59) were affected, with pleural effusions being the most common pleural complication $(32 \%)$ (Table 1). Most pleural effusions are bilateral, reactive exudates to pneumonias, subpleural abscesses or septic embolic infarctions (1). A subpleural necrotizing pneumonia or lung abcess can also spread directly into the pleural space, causing either an empyema (14\%) or pneumothorax (12\%) (Table 1). 
Cardiac complications, on the other hand, are distinctly uncommon, observed in three of the $59(5 \%)$ patients (Table 1). However, all of these patients died, with the diagnoses of myocardial microabscesses (two patients) $(10,11)$ and purulent pericarditis (one patient) (8) being made on postmortem examination only. Patients with myocardial microabscesses can suffer a cardiac arrest $(10,11)$ or other malignant arrhythmia (11). In this review, we did not identify any cases of endocarditis, although this complication has been previously reported in older literature (24).

It is surprising that mediastinitis is not more prevalent, especially given the high incidence of deep neck and pleuropulmonary sepsis. In the present series, the incidence was 3\% (Table 1), with only two cases in the past 25 years $(1,3-5,8)$. Both patients had a fatal outcome; in one patient, the diagnosis was made late in his hospital course, while, in the other, it was made postmortem (8).

Many of the patients in the present series had multiple cardiothoracic complications (59\%). Thus, it is not surprising that respiratory failure and the need for mechanical ventilation was quite frequent (29\%). In 59\% (10 of 17) of these patients, the reason for respiratory failure was ARDS (17\% overall incidence) (Table 1). Sixty per cent (six of 10) of patients with ARDS died $(8,9,11,12)$. Overall mortality for the present series was $10 \%$ (Table 1), suggesting that diagnosis of Lemierre syndrome is still not being made in a timely fashion (3-5).

The patient in the present case report had a unique clinical course. Not only did he have all of the above pleuropulmonary complications, respiratory failure and ARDS, but he also experienced massive hemoptysis. This complication has not been reported in the Lemierre syndrome. The cause was probably multifactorial, with anticoagulation therapy, lung abscesses and necrotizing pneumonia contributing.

Intravenous antibiotics such as penicillin, metronidazole or clindamycin are the mainstay of treatment. For those with pulmonary involvement, it is recommended that antibiotics continue until complete resolution of abscesses and infiltrates is observed on chest x-ray (usually six to eight weeks) (14). Patients with persistent or uncontrolled sepsis require active investigation to identify and drain purulent collections such as oropharyngeal abscesses, pyoarthrosis, empyemas, mediastinitis and unresolving lung abcesses $(8,19,26-28)$. The role of anticoagulation is controversial. Some authors suggest that it may hasten clinical resolution, although the evidence for this is anecdotal (14). However, anticoagulation carries with it the potential risks of serious hemorrhage, as in our patient (25). If septicemia and septic emboli persist despite all of the above measures, then internal jugular vein ligation or excision should be considered, although it has seldom been required (3\% in the present series) $(16,29)$.

Although uncommon, Lemierre syndrome should be considered in a previously healthy adolescent or young adult who has had a recent oropharyngeal infection and who develops septicemia, especially if they have multiple pleuropulmonary complications. Early recognition using a CT scan, rapid institution of intravenous antibiotics and timely drainage of purulent collections are required for a successful outcome.

\section{REFERENCES}

1. Golpe R, Marin B, Alonso M. Lemierre's syndrome (necrobacillosis). Postgrad Med J 1999;75:141-4.

2. Lemierre A. On certain septicemias due to anaerobic organisms. Lancet 1936;1:701-3.

3. Hagelskjaer LH, Prag J, Malczynski J, Kristensen JH. Incidence and clinical epidemiology of necrobacillosis, including Lemierre's syndrome, in Denmark 1990-1995. Eur J Clin Microbiol Infect Dis 1998;17:561-5.

4. Sinave CP, Hardy GJ, Fardy PW. The Lemierre syndrome: suppurative thrombophlebitis of the internal jugular vein secondary to oropharyngeal infection. Medicine (Baltimore) 1989;68:85-94.

5. Eykyn SJ. Necrobacillosis. Scan J Infect Dis Suppl 1989;62:41-6.

6. Weesner CL, Cisek JE. Lemierre syndrome: the forgotten disease. Ann Emerg Med 1993;22:256-8.

7. Barker J, Winer-Muram HT, Grey SW. Lemierre syndrome. South Med J 1996;89:1021-3.

8. Moller K, Dreijer B. Post-anginal sepsis (Lemierre's disease): a persistent challenge. Presentation of 4 cases. Scan J Infect Dis 1997;29:191-4.

9. Paaske PB, Rasmussen BM, Illum P. Fusobacterium pneumonia and death following uvulo-palato-pharyngoplasty. Head Neck 1994; 16:450-2.

10. Adler J, Chakera TM, Thompson R. Necrobacillosis. Australas Radiol 1990;34:256-9.

11. Golledge CL, Beaman MH, Weeramanthri T, Riley TV. Necrobacillosis - primary anaerobic septicaemia due to Fusobacterium necrophorum. Aust N Z J Med 1990;20:702-4.

12. Vohra A, Saiz E, Ratzan KR. A young woman with a sore throat, septicaemia, and respiratory failure. Lancet 1997;350:928.

13. Carlson ER, Bergamo DF, Coccia CT. Lemierre's syndrome: two cases of a forgotten disease. J Oral Maxillofac Surg 1994;52:74-8.

14. Leugers CM, Clover R. Lemierre syndrome: postanginal sepsis. J Am Board Fam Pract 1995;8:384-91.

15. Gong J, Garcia J. Lemierre's syndrome. Eur Radiol 1999;9:672-4.
16. Lustig LR, Cusick BC, Cheung SW, Lee KC. Lemierre's syndrome: two cases of postanginal sepsis. Otolaryngol Head Neck Surg 1995; 112:767-72.

17. Hagelskjaer LH, Pedersen G. Fusobacterium necrophorum septicemia complicated by liver abscess: A case report. APMIS 1993;101:904-6.

18. Karanas YL, Yim KK, Shuster BA, Lineaweaver WC. Lemierre's syndrome: a case of postanginal septicemia and bilateral flank abscesses. Ann Plast Surg 1995;35:525-8.

19. Stahlman GC, DeBoer DK, Green NE. Fusobacterium osteomyelitis and pyarthrosis: a classic case of Lemierre's syndrome. J Pediatr Orthop 1996;16:529-32.

20. Hughes CE, Spear RK, Shinabarger CE, Tuna IC. Septic pulmonary emboli complicating mastoiditis: Lemierre's syndrome revisited. Clin Infect Dis 1994;18:633-5.

21. Williams A, Nagy M, Wingate J, Bailey L, Wax M. Lemierre syndrome: a complication of acute pharyngitis. Int J Pediatr Otorhinolaryngol 1998;45:51-7.

22. Gupta M, Castello FV, Kesarwala HH. Respiratory failure caused by Lemierre's syndrome. Clin Pediatr (Phila) 1995;34:275-7.

23. De Sena S, Rosenfeld DL, Santos S, Keller I. Jugular thrombophlebitis complicating bacterial pharyngitis (Lemierre's syndrome). Pediatr Radiol 1996;26:141-4.

24. Adams J, Capistrant T, Crossley K, Johanssen R, Liston S. Fusobacterium necrophorum septicemia. JAMA 1983;250:35.

25. Guimaraes CA. Massive hemoptysis. In: Pearson FG, Heibert CA, Deslauriers J, et al, eds. Thoracic Surgery. New York: Churchill Livingstone, 1995:581-96.

26. Chalstrey SE, Williams HO, Reilly G. Necrobacillosis - an unusual case of cervical abscess. J Laryngol Otol 1992;106:374-5.

27. Ahkee S, Srinath L, Huang A, Raff MJ, Ramirez JA. Lemierre's syndrome: postanginal sepsis due to anaerobic oropharyngeal infection. Ann Otol Rhinol Laryngol 1994;103:208-10.

28. Dykhuizen RS, Olson ES, Clive S, Douglas JG. Necrobacillosis 
(Lemmiere's syndrome): a rare cause of necrotizing pneumonia. Eur Respir J 1994;7:2246-8.

29. Alvarez A, Schreiber JR. Lemierre's syndrome in adolescent children - anaerobic sepsis with internal jugular vein thrombophlebitis following pharyngitis. Pediatrics 1995;96:354-9.

30. Gudinchet F, Maeder P, Neveceral P, Schnyder P. Lemierre's syndrome in children: high-resolution CT and color Doppler sonography patterns. Chest 1997;112:271-3.

31. Currie PF, Nathwani D, Anderson DN, Smith CC. Necrobacillosis revisited. Br J Hosp Med 1994;52:175-6.

32. Cosgrove EF, Colodny SM, Pesce RR. Adult respiratory distress syndrome as a complication of postanginal sepsis. Chest 1993;103:1628-9.

33. Dellamonica P, Bernard E. 'Deep throat' cellulitis. J Infect 1999;38:134.

34. Venkataraman MT, Policar M. Fever, sore throat, and pulmonary infiltrates in a 20-year-old man. Chest 1997;112:268-70.

35. Chippindale AJ, Patel B, Mamtora H. A case of necrobacillosis. Thorax 1990;45:74-5.

36. Ieven M, Vael K, De Mayer M, De Schepper A, Pattyn S. Three cases of Fusobacterium necrophorum septicemia. Eur J Clin Microbiol Infect Dis 1993;12:705-6.

37. Koay $\mathrm{CB}$, Heyworth $\mathrm{T}$, Burden P. Lemierre syndrome - a forgotten complication of acute tonsillitis. J Laryngol Otol 1995;109:657-61.

38. MacDonald AA, Harar RP, Prior AJ. Necrobacillosis: are we missing the early stages of this life-threatening infection? Lancet 1995;346:1705.

39. Martin MJ, Wright ED. A case of Fusobacterium necrophorum sepsis. J Infect 1995;31:151-2.

40. Meis JF, Polder TW, van de Kar P, Hoogkamp-Korstanje JA. Multiple brain abscesses and bacteremia in a child due to Fusobacterium necrophorum. Infection 1993;21:174-6.

41. Wolf RF, Konings JG, Prins TR, Weits J. Fusobacterium pyomyositis of the shoulder after tonsillitis: Report of a case of Lemierre's syndrome. Acta Orthop Scand 1991;62:595-6.

42. Goyal M, Sharma R, Jain Y, Gupta A, Berry M. Unusual radiological manifestations of Lemierre's syndrome: a case report. Pediatr Radiol 1995;25(Suppl 1):S105-6.

43. Page Y, Comtet C, Tardy B, et al. Disseminated intravascular coagulation in Fusobacterium necrophorum septicemia. Scan J Infect Dis 1990;22:743-7.

44. Mane S, Torres M, Buges J, et al. Scintigraphic demonstration of jugular obstruction in a case of Lemierre syndrome. Clin Nucl Med 1992;17:233-5.

45. Gibb PA, Donell ST, Dowd GS. Near-fatal necrobacillosis presenting as septic arthritis of the knee: a case report. J Bone Joint Surg [Am] 1990;72:1250-3.

46. Carrie S, Fenton PA. Necrobacillosis - an unusual case of pharyngotonsillitis. J Laryngol Otol 1994;108:1097-8. 


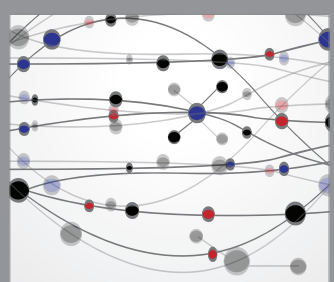

The Scientific World Journal
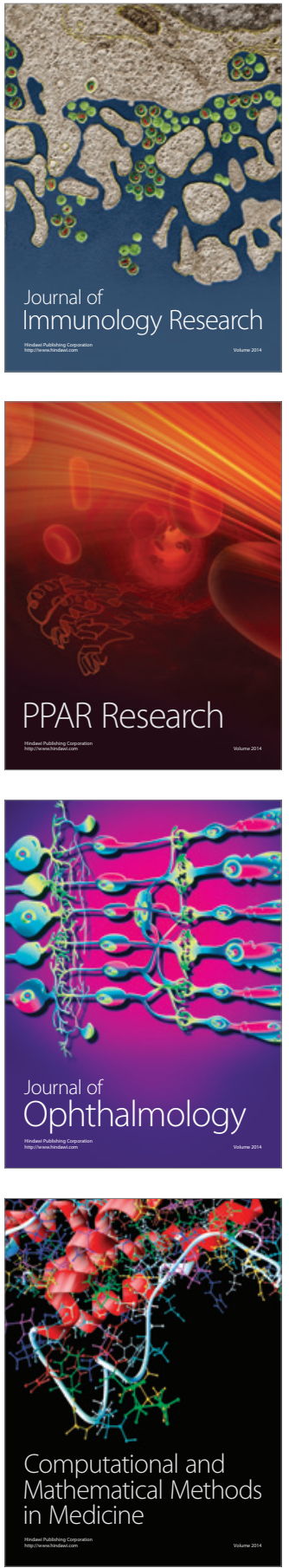

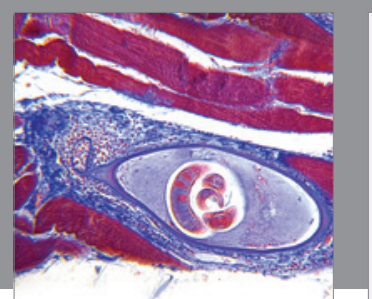

Gastroenterology Research and Practice

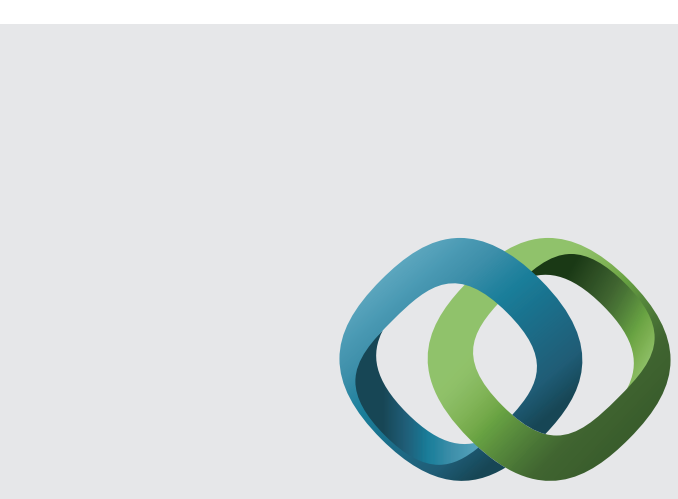

\section{Hindawi}

Submit your manuscripts at

http://www.hindawi.com
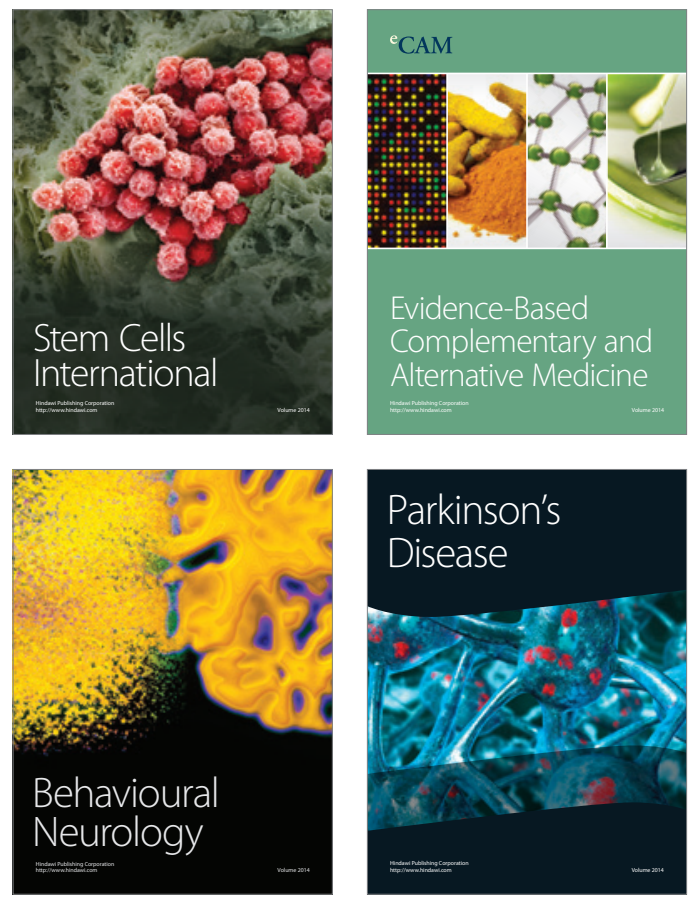
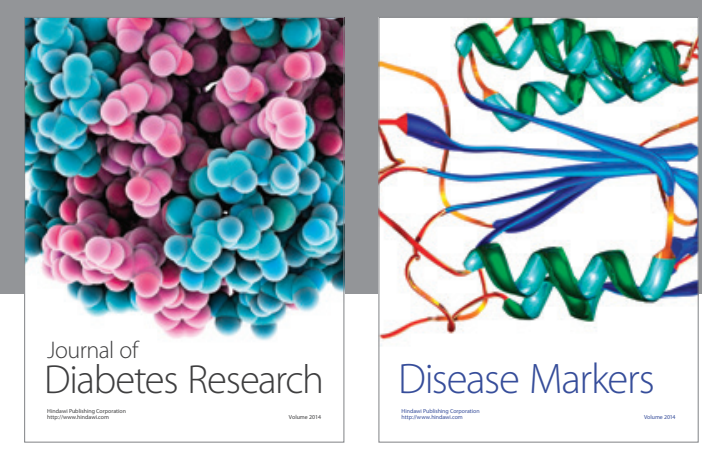

Disease Markers
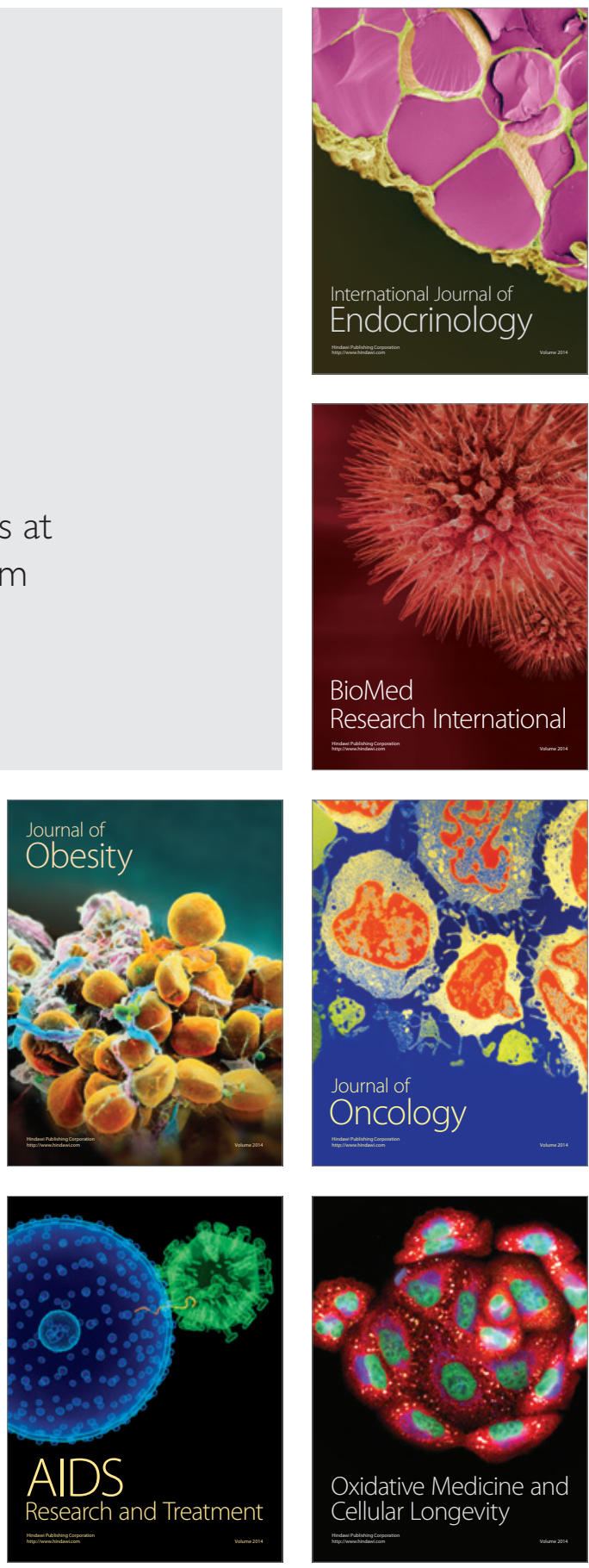